\title{
A PAISAGEM COMO FONTE HISTÓRICA E COMO PRODUTORA DE MEMÓRIA
}

LANDSCAPE AS A SOURCE OF HISTORY AND PRODUCER OF MEMORY

Angelo Aparecido Priori* angelopriori@uol.com.br

Letícia Aparecida da Paixão** leepaixao@gmail.com

RESUMO: O objetivo deste artigo é realizar uma discussão sobre o uso da paisagem como fonte para a história, bem como sua elaboração na produção de memória. A sociedade produz e reproduz o seu espaço de acordo com as suas necessidades e com os recursos técnicos e econômicos de que dispõe. À medida que ela vai se modificando, marcas e heranças das atividades econômicas do passado vão se registrando na paisagem. Produzida historicamente pelos homens, segundo a sua organização social, o seu grau de cultura e o seu aparato tecnológico, a paisagem é o reflexo da organização social e de condições naturais particulares. Portando, constitui-se em um espaço natural, social e histórico. Para a sustentação destes argumentos, utilizaremos a metodologia da História da Ambiental. Ao fazer uma análise histórica das paisagens, consideramos que elas são sistemas abertos, submetidos permanentemente a fatores aleatórios - entre os quais os variados tipos de ação humana. A paisagem é o lugar de projeções e simbolizações de sentimentos e ações humanas, bem como o lugar onde se articulam o social e sua representação, a matriz simbólica onde a experiência coletiva se enraíza e se reflete ao mesmo tempo.

PALAVRAS-ChAVE: Paisagens; Natureza; Memória; História.

ABSTRACT: The use of landscape as a source of History and as a producer of memory is discussed. Society produces and reproduces its space according to necessities and with the technical and economic resources available. As the landscape modifies itself, hallmarks and remains of past economical activities are registered on the landscape. Historically produced by mankind according to its social organization, culture degree and technological progress, the landscape reflects social organization and specific natural conditions. It therefore becomes a natural, social and historical space. The methodology of Environmental History foregrounds the arguments. When the landscapes' historical analysis occurs, they are open systems permanently undergoing random factors, among which may be mentioned the different human activities. Landscape is the place of projections and symbolizations of feeling and human actions and the place in which social activities and their representation are developed. It is rather the symbolical matrix where collective memory is rooted and simultaneously reflected.

KEYWORDS: Landscapes; Nature; Memory; History.

\section{Introdução}

A emergência de problemas ambientais em escala planetária fez com que os historiadores se defrontassem com a necessidade de repensar alguns dos aspectos teóricos e metodológicos de sua disciplina, de maneira a possibilitar a compreensão das profundas interações entre os seres humanos e a natureza ao longo da história. Neste contexto, entra em cena a história ambiental, que oferece um vasto campo de reflexão, abrangendo desde a necessidade de esclarecer seus principais conceitos e aprimorar sua metodologia, até a

\footnotetext{
* Doutor em História. Professor do Programa de Pós-Graduação em História da UEM

** Mestre em História pela Universidade Estadual de Maringá 
análise da forma como os historiadores têm abordado a relação entre os seres humanos e a natureza (CASTRO, 2003).

A história ambiental como campo de estudo organizado e consolidado é um fenômeno relativamente recente. Nos Estados Unidos se fortaleceu por volta da década de 1970. Na América Latina começou a ganhar corpo na década de 1980 (LEFF, 2005). No Brasil, mais tarde ainda. Os primeiros estudos de fôlego surgiram na década de 1990. Para alguns historiadores ambientais, entre eles Donald Worster, havia "pouca história no estudo da natureza e pouca natureza no estudo da história", tornando-a quase uma "história inatural", já que consistia em pesquisas arquivais e com abordagens onde a "terra" aparecia cada vez menos. Com o avanço da história ambiental, esse cenário vai mudando gradualmente e nessa nova história natural, o próprio ambiente é concebido como um documento histórico que o historiador procura "Ier" (MATHEWSON; SEEMANN, 2008, p. 72-73).

Durante longo tempo, os estudos históricos, com algumas exceções, se concentraram exclusivamente na análise das sociedades humanas, como se a natureza fosse apenas mais um entre tantos fatores presentes na história dos homens. Quase que explicitamente, negava-se a possibilidade de pensar as múltiplas e ricas relações entre os seres humanos e o meio natural, como se elas pouco ou nada tivessem a ver com o desenvolvimento histórico das diferentes sociedades (CASTRO, 2003).

Esta tendência de pensar a natureza em oposição ao homem ou a cultura é marcante desde o final do século XVIII. Teixeira da Silva (1997) pontuou que o idealismo e o romantismo alemães do século XIX, forçaram uma distância absoluta entre natureza e cultura. Tal visão contaminou fortemente a história, como as demais ciências sociais, de forma a estabelecer uma periodização em que ambos os termos aparecessem como pontas opostas de um processo.

Porém essa visão de distanciamento cedeu espaço para uma nova compreensão. Essa visão, segundo Teixeira da Silva (1997), se estabeleceu num processo continuum, ou seja, as novas abordagens começaram a privilegiar a natureza como um produto de uma prolongada atividade humana. A incorporação das grandes massas de adensamento humano e seu peso sobre o meio ambiente impôs-se como tema ao historiador.

Nesse sentido, a História Ambiental tem como o objetivo compreender e estabelecer a relação do homem com a natureza, problematizando essas relações e suas transformações 
ao longo do tempo, como também proporcionar conhecimento sobre o nosso atual contexto ambiental.

\section{História, natureza e paisagem}

Muitos foram os estudiosos que se destacaram no estudo da natureza. Entre eles, podemos referenciar o historiador estadunidense Donald Worster. Em seu artigo Para fazer história ambiental (de 1988 e publicado no Brasil em 1991), o professor alerta que a história ambiental rejeita a premissa convencional de que a experiência humana se desenvolveu sem restrições naturais, de que os humanos são uma espécie distinta e "supernatural", de que as consequências ecológicas dos seus feitos passados podem ser ignoradas.

A História Ambiental reúne os temas mais antigos com os mais recentes na historiografia contemporânea: a evolução das epidemias e do clima como parte integrante do ecossistema humano; a série de calamidades naturais agravadas por uma antevisão, ou mesmo por uma absurda "disposição" dos colonizadores simplórios; a destruição da natureza, causada pelo crescimento populacional e/ou pelos predadores do hiperconsumo industrial; as mazelas da origem urbana e industrial, que levam à poluição do ar e da água; o congestionamento humano ou os altos níveis de ruído nas áreas urbanas, num período de urbanização galopante (WORSTER, 1991, p. 200-201).

Essa nova abordagem historiográfica busca estabelecer uma ligação entre a história natural e a história social. A partir dessa ligação e de observações das relações entre comunidades e os seus meios naturais, Drummond (1997) enumerou cinco características dos estudos da História Ambiental, que vale a pena registrar.

A primeira característica é que quase todas as análises focalizam uma região geográfica com algum grau de homogeneidade natural. Estuda-se uma região árida, o vale de um rio, uma ilha, um trecho de terras florestadas. Desse modo, a história ambiental quase sempre tem parentesco com a história regional na sua ênfase em processos locais ou geograficamente circunscritos, embora as regiões estudadas sejam mais 'naturais' do que 'sociais'.

Uma segunda característica é o diálogo sistemático com quase todas as ciências naturais aplicáveis ao entendimento dos quadros físicos e ecológicos das regiões estudadas. Os historiadores usam textos básicos e avançados de geologia, geomorfologia, climatologia, 
meteorologia, biologia vegetal e animal e ecologia. Portanto, a história ambiental é interdisciplinar. Depende de outras ciências para sua melhor compreensão.

A terceira característica da História Ambiental é explorar as interações entre o quadro de recursos naturais úteis e os diferentes estilos ou níveis civilizatórios das sociedades humanas. As ciências naturais mais uma vez contribuem para o entendimento "material" do conjunto de recursos naturais disponíveis, mas é principalmente na história das civilizações, na antropologia cultural e na geografia econômica que os historiadores ambientais encontram um repertório de conceitos, estudos empíricos e enfoques que permitem avaliar as diferentes formas de uso dos recursos.

A quarta característica é a grande variedade de fontes. Os historiadores ambientais usam fontes tradicionais da história econômica e social, como censos populacionais, econômicos e sanitários, inventários de recursos naturais, imprensa, documentos governamentais, diários e correspondências. Os relatos de viajantes, exploradores e cientistas europeus, que se expandiram pelo mundo a partir do fim do século XV, são outra fonte fundamental. Mas a paisagem ainda é uma fonte pouco explorada pelos historiadores.

A última característica apontada por Drummond é o trabalho de campo. Ir pessoalmente até o local para entrevistar os moradores, consultar os arquivos locais e conversar com os cientistas que trabalham na região. O trabalho de campo serve para identificar as marcas deixadas na paisagem pelos diferentes tipos humanos.

Com relação às fontes é importante destacar algumas que são utilizadas para as análises das paisagens: códigos de posturas, registros fundiários, livros ou tratados de agronomia, a arqueologia, inclusive a industrial, relatos de viajantes e, naturalmente, a iconografia. Velhas e conhecidas fontes utilizadas pelos historiadores, mas que devem ser lidas à luz de novos objetos e de novos problemas.

Com relação às fontes, a História Ambiental enfrenta duas dificuldades. A primeira delas é que as sociedades, de modo geral, são pouco atentas às transformações que ocorrem no seu ambiente. A segunda esta associada à escala de tempo das transformações ambientais. Muitas delas só são perceptíveis na longa duração, mas é bastante raro encontrar registros históricos que cubram as numerosas fases destas transformações de longa duração.

Apesar dessas dificuldades, diversas das fontes apontadas acima já são de uso consagrado pelo historiador. Porém, em relação às novas fontes, como são as paisagens, por 
exemplo, estas requerem, para sua utilização, estratégias específicas de observação e interpretação. A maneira de lidar com essa nova fonte, a paisagem, exige a abertura de diálogo com especialistas de outros campos da ciência naturais. Seja como for, aos historiadores ambientais resta o desafio de inventar as fontes que podem viabilizar a discussão de seus novos problemas (MARTINS, 2007).

O nosso novo problema propõe utilizar a paisagem enquanto um documento histórico, pois por meio dela podemos perceber as modificações da natureza pelo homem, as mudanças ambientais, e também o papel do ambiente no desenvolvimento da sociedade e a relação desta com aquela (MARTINS, 2006).

Sobre a paisagem é necessário realizarmos um diálogo com a Geografia. Na Geografia encontramos diversas teorias que versam sobre a relação do homem com paisagem. $\mathrm{O}$ determinismo ou causalidade defende que as condições naturais governam o comportamento do homem e até mesmo aspectos do seu caráter. Trata-se de uma noção derivada da ideia pós-darwiniana do homem enquanto produto da seleção natural, por inexoráveis processos da natureza. Nesta compreensão, a natureza obedece a um grande plano, ao qual o homem tem de se conformar e, dessa forma, prosperar. Já para a teoria do possibilismo, o homem não é passivo, mas sim um agente geográfico, apto a agir sobre o meio e a modificá-lo, dentro dos limites naturais do espaço e de possibilidades de desenvolvimento (DREW, 1986).

Porém, a teoria do determinismo ou causalidade encontra-se em desuso. O geógrafo Carl Sauer, em texto clássico, publicado no distante ano de 1925, já havia constatado que a importância da ação humana na produção e transformação da paisagem era muito mais significativa do que a influência do meio ambiente sobre o uso da terra (SAUER, 2006). ${ }^{1}$

Ao enfatizar a ação humana na transformação da paisagem, Sauer constatou que sob uma perspectiva histórica, pode-se diferenciar "paisagens naturais" (definidas como áreas anteriores às atividades humanas) e "paisagens culturais" que correspondem aos processos de modificação da paisagem natural por meio da ação e das obras humanas. Em outras palavras, são as atividades humanas transformadoras e não as influências dos elementos naturais, que ocupam uma posição central nos estudos da paisagem: "a cultura é o agente, a

\footnotetext{
${ }_{1}^{1}$ Para este artigo, utilizamos a versão do texto de Carl Sauer traduzida para o espanhol e publicada pela revista Polis, em 2006. Existe uma versão do texto em português, que foi inserida no livro organizado por Correa e Rosendhal (1998).
} 
área natural é o meio, a paisagem cultural é o resultado", concluiu Sauer (2006, § 70). Dessa forma, a paisagem do presente é a consequência histórica da interação entre o homem e o ambiente.

David Drew (1986) também defende a importância do homem na alteração do meio físico. Segundo o autor, o homem não só pode transformar e expandir o seu nicho, mas também afetar os mecanismos do sistema da Terra em maior ou menor grau, em maior ou menor escala. Ele vem procurando, em ritmo acelerado, modificar o ambiente para se contentar a si mesmo, em vez de mudar seus hábitos para melhor se adaptar ao ambiente.

O termo "ação antrópica" é utilizado pela Geografia para se referir às transformações da paisagem a partir da ação do homem como coletivo social. Porém, com o aumento dos desastres ecológicos ocasionados pela atividade humana e, consequentemente, da intensificação da conscientização, o termo acabou adquirindo um sentido pejorativo. Passos (1997) inferiu que quando um texto de Geografia ou de Ecologia faz referência a uma "ação antrópica", tem-se uma conotação negativa para todas as mudanças ambientais. O autor propõe que para julgar a intervenção do homem sobre o meio, é necessário conhecer bem todas as circunstâncias que promoveram essa intervenção, sobretudo, com uma perspectiva temporal, isto é, histórica.

Para tanto, devemos ter uma visão global e diretamente explicativa dos fenômenos naturais e de suas interações, assim como uma orientação francamente biológica. As transformações históricas e dinâmicas atual das paisagens devem ser abordadas a partir de uma análise integrada, com ênfase nas relações existentes entre os elementos, isto é, com ênfase nos processos determinantes das construções paisagísticas (PASSOS, 1997, p. 71). Assim, podemos pensar que a nova relação da sociedade com seu espaço não são, portanto, um dado, mas um produto construído por um processo cultural e social (SALGUEIRO, 2001).

Embora apresente ser uma disciplina nova, com uma densidade teórica ainda frágil e poucos exemplos práticos, a história das paisagens é um campo antigo - mais antigo do que a história social ou a história demográfica. Estudiosos alemães, franceses e ingleses especialmente na década de 1930 - produziram obras que delimitaram, entre a geografia humana ou histórica e a história agrária, um novo campo (TEIXEIRA DA SILVA, 1997). Tais estudos observaram que o processo de percepção da natureza reside nas transformações físicas, ecológicas, sociais e culturais sofridas pelas paisagens, que surgem como reflexo, como forma aparente e resultado da interação do homem com a natureza. 
Karl Marx em seus manuscritos econômico-filosóficos de 1844, já nos alertava para a relação interdependente do homem com a natureza, cujos comportamentos refletem-se mutuamente. Para o filósofo, a sociedade era a plena "unidade [...] do homem com a natureza" (MARX, 1978, p. 175) e enfatizava que "o homem vive da natureza, isto é, a natureza é seu corpo, e tem que manter com ela um diálogo ininterrupto se não quiser morrer. Dizer que a vida física mental do homem está ligada à natureza significa simplesmente que a natureza está ligada a si mesma, porque o homem dela é parte" (MARX, 1978, p. 213).

Pode-se afirmar que a história ambiental surge das preocupações da sociedade com o meio ambiente, amplamente visíveis a partir das últimas décadas.

De acordo com Silveira (1998) a sociedade produz e reproduz o seu espaço de acordo com as suas necessidades e com os recursos técnicos e econômicos de que dispõe. À medida que ela vai se modificando, marcas e heranças das atividades econômicas do passado vão se registrando na paisagem. Nesse sentido, Passos (1997), afirmou que a paisagem é produzida historicamente pelos homens, segundo a sua organização social, o seu grau de cultura e o seu aparato tecnológico. Dessa forma, a paisagem é, portanto, um espaço de três dimensões: natural, social e histórica.

Contudo, não podemos deixar de destacar a dimensão afetiva, ou seja, a noção de pertencimento que o homem tem da paisagem, ou ainda, as lembranças que essa paisagem remete. Estamos habituados a situar a natureza e a percepção humana em dois campos distintos, embora elas sejam inseparáveis. Antes de poder ser um repouso para os sentidos, a paisagem é obra da mente. A paisagem compõe-se tanto de camadas de lembranças quanto de estratos de rocha: "se a visão que uma criança tem da natureza já pode comportar lembranças, mitos e significados complexos, muito mais elaborada é a moldura através da qual nossos olhos adultos contemplam a paisagem" (SCHAMA, 1996, p. 17).

É importante refletirmos sobre a natureza e sobre nossas relações físicas complexas com o mundo natural, pois a natureza que carregamos dentro de nós é tão importante quanto à natureza que nos cerca. O historiador estadunidense Willian Cronon diz que a "natureza que está dentro de nós pode ser considerada como o motor que dirige nossas interações com a natureza física, neste contínuo processo de transformação homem/natureza" (apud FREITAS, 2002, p. 159). 
Quando reconhecemos os legados da memória que a natureza produz, admitimos que nem sempre a paisagem pode ser um local de mero prazer. Por exemplo, em 1963, ocorreu um incêndio florestal no Estado do Paraná de proporções sem precedentes. O fogo consumiu e modificou aproximadamente 600 mil alqueires da paisagem florestal do Estado:

Todo o Paraná central ardeu numa só fogueira colossal que em poucos dias arrasou
mais de seiscentos mil alqueires de matas, pastagens e lavouras, destruindo casas,
sítios, fazendas, ceifando vidas humanas. Pouco restou da zona rural e das imensas
reservas florestais, nativas e cultivadas, dos municípios situados na rota do flagelo
(GOVERNO DO ESTADO DO PARANÁ, 1964, p. 16).

A população, agoniada, comparou seu território ao inferno: "Sêca, geada e fogo. Este é o ano da penitência! O demônio reinou por aqui e trouxe todo o fogo do inferno com ele" (apud GOVERNO DO ESTADO DO PARANÁ, 1964, p.16).

Esses incêndios tiveram início com a prática de queimada do campo. O fogo é um dos mais antigos instrumentos utilizados pela espécie humana para o manejo e ocupação da terra. As civilizações antigas utilizavam o fogo para limpar a terra e prepará-la para o cultivo agrícola, para encurralar a caça, para facilitar a passagem por entre a vegetação e como ferramenta de guerra. Não podemos deixar de pensar no fogo como o elemento de aniquilação. Todavia, tanto os mitógrafos quanto os historiadores da natureza sabem que da pira surge a fênix, que a vida reconstituída pode lançar um rebento por entre uma densa camada de cinzas (SCHAMA, 1996, p. 30).

Ao recuperar "memórias" como estas da população paranaense, extasiada diante do fogo ("o fogo do inferno" na percepção popular) precisamos ter o cuidado para que suas explicações não se apresentem superficiais e/ou infundadas. Afinal, o tempo e as experiências podem modificar as lembranças dos indivíduos, podendo deformar as recordações passadas, tornando-as, como lembra Pierre Nora (1993), inconsciente de suas deformações, vulnerável a toda utilizações e manipulações, suscetível de longas latências e de súbitas revitalizações.

Nesse sentido, para as pesquisas históricas sobre paisagens que sofreram ou sofrem a intervenção humana é sempre necessário manter um diálogo entre a memória e a história, pois a primeira é "essencialmente mítica, deformada, anacrônica, mas constitui o vivido desta relação nunca acabada entre o presente e o passado" enquanto que a segunda deve “esclarecer a memória e ajudá-la a retificar os seus erros" (LE GOFF, 1992, p. 29). 
função das mudanças e dos relatos públicos sobre o passado. Que memórias escolhemos para recordar e relatar (e, portanto, relembrar) e como damos sentido a elas são coisas que mudam com o passar do tempo (THOMSON, 1997, p.57).

Nossas memórias, portanto, são carregadas de subjetividades: as reminiscências pessoais transmitem os significados que atribuímos aos acontecimentos. Muitas vezes essas memórias não condizem com os fatos, mas são úteis aos historiadores na medida em que Ihes permitem explorar a relação entre reminiscências pessoais e memória coletiva, observando as razões pelas quais as pessoas apresentam formas específicas de narrar suas experiências históricas. Portanto, ao tratar o tema das relações entre os homens e a natureza, devemos substituir a perspectiva antropocêntrica por uma compreensão da natureza como resultado de práticas culturais e como algo que é sempre e, essencialmente, representada pelos seres humanos a partir de suas vivências e experiências sociais.

\section{Considerações finais}

A paisagem é constituída por componentes naturais e artificiais. Por meio dela podemos perceber as modificações na natureza pelo homem, as mudanças ambientais, o papel do ambiente no desenvolvimento da sociedade, bem como as relações estabelecidas entre homem e a natureza. O elemento fundamental presente em qualquer paisagem é o tempo, pois ele age em determinado espaço físico, com a predominância de certos elementos, para formar os diversos tipos de paisagens.

No caso da análise histórica das paisagens deve-se considerar que são sistemas abertos, submetidos permanentemente a fatores aleatórios - entre os quais os variados tipos de ação humana - cujos resultados não são previsíveis. Partindo do aporte fornecido pela antropologia e atentos a uma postura não-funcionalista da natureza, e contrária a qualquer reducionismo geográfico, propusemos uma análise holística da questão. Assim, a paisagem, longe de se constituir em um dado da geografia, aparece - tal como na abordagem antropológica - como uma resultante de variados fatores, todos fundamentais na organização do espaço. A paisagem não é uma natureza intocável, mas sim uma natureza "antropizada", que passou por processos de alterações significativos devido à interferência humana. Nesse sentido, a paisagem é o resultado material de interações entre processos físicos, ecológicos, sociais e culturais.

Portanto, a natureza precisa ser compreendida como parte e resultado de uma longa história cultural. Seres humanos e natureza não se distanciam e não podem ser vistos 
separadamente. A paisagem é o lugar de projeções e simbolizações de sentimentos e ações humanas, bem como o lugar onde se articulam o social e sua representação, a matriz simbólica onde a experiência coletiva se enraíza e se reflete ao mesmo tempo.

\section{Referências}

CASTRO, Maria Inês M. Reflexões sobre a história ambiental. Revista Universitas FACE, Brasília, v. 1, n. 1, p. 2544, 2003.

CORREA, Roberto Lobato; ROSENDHAL, Zeny (Org.). Paisagem, tempo e cultura. Rio de Janeiro: Ed. UERJ, 1998.

DREW, David. Processos interativos homem - meio ambiente. São Paulo: Difel, 1986.

DRUMMOND, José Augusto. Devastação e preservação ambiental no Rio de Janeiro. Niterói: EDUFF, 1997.

FREITAS, Inês Aguiar de. A geografia na construção de uma história ambiental brasileira. Boletim Goiano de Geografia, Goiânia, v. 22, n. 2, p. 155-168, jul./dez. 2002.

GOVERNO DO ESTADO DO PARANÁ. Paraná: do flagelo à recuperação. Curitiba: Departamento de Imprensa Oficial, 1964.

LE GOFF, Jacques. História e Memória. 2ª̣ed. Campinas: Editora da UNICAMP, 1992.

LEFF, Enrique. Vetas y vertientes de la história ambiental latinoamericana: una nota metodológica y epistemológica. Vária, Belo Horizonte, n. 33, p. 17-35, 2005.

MARTINS, Marcos Lobato. História e Meio Ambiente. São Paulo: Annablume, 2007.

MARX, Karl. Manuscritos econômicos-filosóficos: terceiro manuscrito. In: MARX, Karl. Manuscritos econômicofilosóficos e outros textos escolhidos. 2a. ed. São Paulo: Nova Cultural, 1978. p. 165-214. Coleção os pensadores.

MATHEWSON, Kent; SEEMANN, Jörn. A geografia histórico-cultural da Escola de Berkeley: um precursor ao surgimento da História Ambiental. Varia, Belo Horizonte, v. 24, n. 39, p.71-85, jan/jun. 2008.

NORA, Pierre. Entre a memória e a história: a problemática dos lugares. Projeto História, São Paulo, n. 10, p. 727, dez. 1993.

PASSOS, Messias Modesto dos. Eco-história da paisagem. Boletim de Geografia, Maringá, v. 15, n. 1, p. 69-83, 1997.

SALGUEIRO, Teresa Barata. Paisagem e geografia. Revista Finisterra, v. XXXVI, n. 72, p. 37-53, 2001.

SAUER, Carl O. La morfologia del paisaje. Polis. Revista Latinoamericana, n. 15, 2006. Disponível em: www.revues.org. Acessado em: 17 jun. 2013.

SCHAMA, Simon. Paisagem e memória. São Paulo: Companhia das Letras, 1996.

SILVEIRA, Leonor Marcon. A ocupação e organização espacial do território paranaense face aos recursos da natureza. Acta Scientiarum, Maringá, v. 20, n. 1, p. 129-136, 1998.

TEIXEIRA DA SILVA, Francisco Carlos. História das Paisagens. In: CARDOSO, Ciro Flamarion; VAINFAS, Ronaldo (Orgs.). Domínios da História: ensaios de teoria e metodologia. Rio de Janeiro: Campus, 1997.

THOMSON, A. Recompondo a memória: questões sobre a relação entre a História Oral e as memórias. Projeto História, São Paulo, n. 15, p. 51-84, abr. 1997.

WORSTER, Donald. Para fazer história ambiental. Estudos Históricos, Rio de Janeiro, v. 4, n. 8, p. 198-215, 1991. 